ISSN(print): 2644-0490, ISSN(online): 2644-0504

Volume 4 Issue 05 May 2021

Article DOI: 10.47191/jefms/v4-i5-25, Impact Factor: 6.228

Page No.- 575-596

\title{
The Importance of Marketing Research Practices on the Performance of Tanzanian Manufacturing SMEs.
}

\author{
Dr. Upendo Brilliant Cornell Nyamanza \\ Lecturer, Department of Business Administration, College of Business Education,
}

ABSTRACT: Despite increased competition across the globe, Small and Medium Enterprises (SMEs) are generally said to be behindhand in the execution of formal marketing research. This study, investigated the importance of marketing research practices on the performance of manufacturing SMEs in Dar es Salaam, Tanzania. Within quantitative method, an analytical survey design was adopted and data was randomly collected from 200 SMEs using semi-structured questionnaire and analyzed using descriptive statistics, cross-tabulation, T-test, and regression analyses through SPSS software: 21

Findings confirm that the majority of manufacturing SMEs in Dar es Salaam do implement marketing research activities in unstructured way. However, an independent $t$-test reveal that a significant difference exists at $5 \%$ level with SMEs which adopts formal marketing research being more likely to grow $(p$-value $=0.009)$. Further, the majority of SMEs utilises marketing research information generated by external agents based on personal networks due to pressure from competitive environment and resource constraints. This way, there are no statistical and significant relationships between SMEs performance and the extent of utilising marketing research data generated by external agents at $5 \%$ level of chi-square statistics $\left(X^{2}=14.975 ; 4\right.$ d.f.). Consequently, the regression analysis indicates a significant value less than 0.05 with an adjusted R-square of 0.029 . In lieu of this, the extent of executing marketing research activities are on average associated with the performance of SMEs. This is similar to the work of others (Ghouri, Khan, Malik, and Razzaq, 2011; McLarty, Pichanic, and Srpova, 2012) and the underlying theories of marketing by SMEs.

The paper proposes a model that can be used to explain the influence of marketing research practices on the performance of SMEs. Also, some recommendations to policy design and marketing practioners including areas for further research are proposed. KEYWORDS: Marketing research practices, SMEs, Manufacturing sector, and Firms' Growth

\section{INTRODUCTION}

It is widely acknowledged that capabilities of Small and Medium Enterprises (SMEs) in implementing marketing activities are important in stimulating business growth (Nyamanza, 2019; Oyedijo, Idris, and Aliu, 2012; Anderson, 2012). For SMEs to be competitive and productive; they must be able to respond quickly and efficiently to both domestic and international market signals to take advantage of trade and investment opportunities (Olomi, 1999; Ebitu, 2016; Nyamanza, 2020). The ability of a firm to perform marketing research activities is fundamental in achieving sustainable competitive advantage and growth. In this perspective, marketing research practices may contribute to the growth of business in many aspects, particularly sales, return on investment, and maintain goodwill (Anderson, 2012; Carson, Gilmore, \& Rocks, 2004). Proper marketing research strategies add excellence in business activities and strengthen the competitiveness and market share (Sohail and Alashban, 2009; Ghouri et al., 2011).

However, marketing research practices are altogether different from region to region, countries to countries, and sector to sector in relation with socio-cultural, and economic backgrounds (Ghouri et al., 2011; Resnick, Cheng, Simpson, and Lourenco, 2016; Nyamanza, 2019). The actual trends, the globalization of markets, and development of technology are among the issues that altogether have enhanced marketing processes which facilitate business opportunities for SMEs (Mbura, 2008; Anderson, 2012). Most studies on the marketing concepts and practices often focused on big size companies because SMEs do not have adequate resources, and market muscles as compared to Multinational corporations (Carson et al., 2004; Anderson, 2011). Nowadays, SMEs perception of the marketing concept has increasingly changed and contends that business achieves success by determining and satisfying needs, wants, and aspiration of target market (see Walsh \& Lipinski, 2009; Nyamanza; 2020). In lieu of this, marketing 


\section{The Importance of Marketing Research Practices on the Performance of Tanzanian Manufacturing SMEs.}

research is uniquely equipped and responsible for analysing environmental changes and translating its observations into recommendations for the redesign of the corporate resource base and its product-market portfolio (Ayanda and Adefemi, 2012). Nonetheless, the marketing function in SMEs is hindered by constraints like poor cash flow, lack of marketing expertise, business size, and strategic customer related problems to mention a few (Nyamanza, 2019; O'Dwyer, Gilmore, and Carson, 2009) and because of this, some scholars have even been questioning if small firms do perform marketing activities or not (see Carson et al., 2004; Gilmore, Carson, and Grant, 2001). Despite such restrictions, SMEs need to successfully utilise marketing research practices to overcome such challenges and generate sale (Walsh and Lipinski, 2009; Ebitu, 2016). Although various scholars have tried to build and improve theoretical and practical models of marketing for Small firms (Anderson, 2012; Siu, 2002; Brooksbank, Garland, and Taylor, 2008) other researchers have presented the way in which strategic marketing research decisions such as knowledge of current market conditions and consumer tastes were definitely linked to SMEs performance (Nyamanza, 2019; Sohail and Alashban, 2009; Buli, 2017).

Consequently, Resnick et al. (2016) went as far as arguing that in the case of SMEs, research on marketing needs to adopt a contingency approach. It is now becoming apparent that the basic principles and practices that apply in one specific environment may not necessarily be relevant and applicable in another (Siu, 2002; Saleh, 2015). Generally, McLarty et al. (2012) perceived most marketing approaches and concepts as being unsuitable for SMEs and not useful in the way their markets are appreciated. But the writers finally deduced that the marketing practices had added value to SMEs performance. In this regard, Owomoyela, Oyeniyi, and Ola (2013) claim that the marketing strategy of SMEs in Nigeria is a vital prerequisite of their ability to strengthen market share; yet they seem to have not performed creditably well (Adewale, Adesola, and Oyewale, 2013). In addition, Shirazi (2017) insists that inconsistencies between the market needs and demand of the customers and marketing processes offered by SMEs caused reduced competitiveness in Tehran. Accordingly, Cooper and Kleinschmidt (2015), mentioned in their studies that the challenges faced by marketers are their inability to demonstrate the effectiveness of marketing activities. It is on this account that market orientation as a driver of SMEs performance has also generated scholars' interest (see Aziz and Yassin, 2010; Walsh and Lipinski, 2009).

A major problem here is that existing theories and practices cannot be taken for granted as tool for understanding the way in which SMEs acts in order to grow (O'Dwyer et al., 2009; Isaga, 2012; Nyamanza, 2019). There has been little consensus among researchers concerning the impact marketing decisions has on business performance particularly marketing research (Sohail and Alashban, 2009; Fu, 2011; Gati, 2015). One stream of research has suggested a positive correlation between a firm size and marketing orientation while other studies have reported little or no support for such a relationship (Shirazi, 2017; Adewale et al., 2013). Despite the broad practices of marketing research into the SMEs sector, from the local studies, we could find no studies about the effects of marketing research practices on SMEs growth with reference to Tanzanian manufacturing sector. Little is known about the effects of marketing research activities on the performance of Tanzanian manufacturing SMEs. This study intends to fill this identified gap. Notably, an empirical analysis of the importance of marketing research practices on the performance of SMEs in Tanzania is required so as to get an insight of the comparison with marketing research practices of foreign research. In order to generate such information, the study envisages to address the following empirical question: "To what extent are Tanzanian manufacturing SMEs' growth affected by marketing research practices?" It is against this backdrop that SMEs owner/managers are aware of the importance of marketing research activities in predicting business growth. Arguably, findings from this study contributes to putting in place measures and implication for policy design. The study findings shall also add value to the existing body of knowledge that can serve as a basis for further research in marketing of SMEs.

The manufacturing SMEs is selected as the focus of this study because it is one of the growing industries in Tanzania (Kiyabo \& Isaga, 2019) and form a significant share of the industrial sector such that their contributions to the economy warrant on-going research (Mahemba, 2003; Anderson, 2012; Nyamanza, 2020). To achieve all these, the study is organized as follows: the literature review is subsequently provided, followed by the methodology, research findings, conclusion and recommendations. Finally, the study highlights on the limitations and avenues for further studies.

\section{LITERATURE REVIEW}

\subsection{Marketing and Manufacturing SMEs}

Generally, a company that efficiently implements marketing techniques does not only attract and retain a loyal set of customers, but also helps to make the world a better place (Blythe, 2006; Kotler, Kartajaya, Setiawan and Wiley InterScience, 2010). Traditionally, marketing was defined as a management process which was responsible for identifying, anticipating, as well as satisfying customer requirements in a profitable way (Nyamanza, 2019; Blythe, 2006). This definition represents a more disciplined marketing management view, in which profitability is the key focus. According to American Marketing Association (2013) marketing is defined as the activity, set of institutions, and processes for creating, communicating, delivering and exchanging 


\section{The Importance of Marketing Research Practices on the Performance of Tanzanian Manufacturing SMEs.}

offerings that have value for customers, clients, partners, and society at large. The theory of marketing has evolved beyond the dominance of the product, price, place and promotion (4Ps) of the marketing model introduced in the 1960s (Ogbu, 2017).

Marketing text book definitions of marketing may not necessarily apply to manufacturing SMEs due to their unique characteristics. Indeed, marketing literature has emphasized a need to develop and refine the attributes of current marketing models to profile the marketing practices in SMEs (Resnick et al., 2016). To date, marketing theories and concepts have been largely exemplified by large organizations and it could be argued that these conventional marketing definitions, theories and models, which are developed based on studies of big companies may not apply to the context of small firms (O'Dwyer et al., 2009; Resnick et al., 2016). Since the literature throws up a number of different approaches to marketing in small business context (e.g. Kotler et al., 2010; Owomoyela et al., 2013; Shirazi, 2017; Gilmore et al., 2001; Sohail and Alashban, 2009; Stoke and Wilson, 2010) then, the personality of the owner manager is a key to any marketing implementation including marketing research (Nyamanza, 2019; Olomi 2001; 2006). This study therefore examines the extent to which marketing research practices as part of traditional marketing theory affects SMEs performance and considers how owner-managers perceive the efficacy in marketing research within a small business setting.

\subsection{Marketing Research as a tool for enhancing SMEs growth potential}

Marketing research is defined by Churchill (1996) as "...the systematic design, gathering, recording, analysis, and interpretation of data about a specific marketing problem facing a company that is geared to providing pertinent information for decision makers to be used in solving a particular marketing problem". Today, the marketing managers are facing more pressures and market challenges than ever; they are thus constantly trying to gather information on the activities of competitors and ascertain changes in the marketing place through their market network (Siu, Fang, and Lin, 2004). In other words, it seems paramount that the marketing manager understands the way that knowledge is acquired in the field and how it can be analysed to get a more complete understanding of customers and markets.

One of the reasons for this is that, in modern economies, the character of most markets is changing rapidly compared to the past thus accumulation of information reduces uncertainties, which in turn adds value to the firm. In this context, customers and marketing information should be considered as vital elements in creating customer satisfaction as the information regarding the products that organisation provides is not sufficient itself (Kotler, Wong, Sunders, and Armstrong, 2008). To be able to effectively compete and distil opportunities in the market, SMEs need to be well informed on what customers actually want and how their needs change in terms of product quality and other attributes as well as how best to maintain a competitive advantage (Mbura, 2008; Anderson, 2012; Mdasha, Irungu, \& Wachira, 2018). Since marketing information is one of the most important resources for any organisation's success (Mbura, 2008) then, to be of any use, the information must be timely, accurate and relevant to that particular problem (Kotler et al., 2008). The reasons and times at which an organisation might consider performing marketing research varies, but the general purpose of gaining intelligence for decision making remains constant throughout (Nyamanza, 2019; Kotler, 2001).

Indeed, marketing research is a key element within the total field of marketing information (Baines, Fill, and Page, 2011; Kotler et al., 2008). It links the customer, consumer, and the public to the marketer through information which is used to identify and define marketing opportunities and problems; generate, refine and evaluate marketing actions; improve understanding of marketing as a process and of the ways in which specific marketing activities can be made more effective. Marketing research therefore, specifies the information required to address these issues; designs the method for collecting information; manages and implements the data-collection process, analyses the results; and communicates the findings and their implications (Churchill, 1996). Likewise, this definition of research has also been adopted with modifications by Blythe (2006) who add that marketing research is used to monitor marketing performance of a firm.

Researchers (Simpson, Padmore, Taylor, and Frecknall-Hughes, 2006; Adewale et al., 2013; Baines et al., 2011; Buli, 2017; Nyamanza, 2019; Mdasha, et al., 2018; Kotler et al., 2010) insist that high performing firms make use of marketing research in their activities. To support this argument (Siu et al., 2004) insist that SMEs performance is positively related with in house market research other than the use of external generated research outputs. Other empirical evidence continues to reaffirm the opinions that prosperous businesses embrace a more pre-emptive and practical rather than responsive technique to the future direction through planning (Kotler et al., 2008).

Nonetheless, the findings of Siu et al. (2004) purport that SMEs in Taiwan operate in an "information void" environment in which market survey data seem to be unreliable. The study insists that owner-manager in Taiwan use an action-driven, experience-based intuitive model to view problems in totality, take a general approach to problems, define parameters intuitively, and make decisions. In this regard, Blythe (2006) as well as Baines et al. (2011) have identified a number of basic stages in the marketing research process that should guide any marketing research project. They include: 


\section{The Importance of Marketing Research Practices on the Performance of Tanzanian Manufacturing SMEs.}

I. Problem definition: Typically, but not always, the problem is described in vague terms as organisations are not always sure what information they are looking for. The marketing researcher then needs to translate the management problem into a researchable manner.

II. Decide the research plan: The researcher has to decide whether or not to undertake primary or secondary search or both. In practice, most projects involve a combination of secondary and primary research, with a desk research phase occurring at the beginning to ensure that a company is not wasting its money on research that has already been conducted. Also, marketing directors need to have some understanding of the different types of study that can be conducted (i.e. exploratory, descriptive, or causal research) because this has an impact on the type of information to be collected, and hence the data that they receive to help them solve their management problem.

III. Data collection and sampling: This involves the field work and the collection of the required data from the relevant sample of the population. So, a questionnaire can be distributed or run the focus group sessions, or conduct telephone surveys, depending on the decisions taken in the first design stage of the field work.

IV. Data analysis and interpretation: This comprises data input, analysis and interpretation. How the data is input basically depends on the type of data collected. Hence, the analysis can be in a form of qualitative or quantitative.

V. Report preparation and presentation: This is the last stage which involves reporting the results and the presentation of the findings to the internal or external client. The results have to be free from bias.

Generally, marketing research data are of little use unless they can be translated into a format that is meaningful to the SMEs manager/owner who initially demanded the data and should be in an acceptable standard. This signalled the need for small firms to anticipate and act on future demands in the market, thereby creating a first-mover advantage vis-à-vis competitors (Buli, 2017). Along this path, the author stresses the importance of considering needs and wants of customers through marketing research activities such that the current trends are evaluated in order to determine a potential effect of marketing research on SMEs performance.

\subsection{SMEs Defined}

There is no specific and generally accepted definitions of micro, small and medium-sized enterprises in Tanzania (Anderson, 2012). This confirms that SMEs are defined differently in different countries depending on the level of development, and most of definitions of SMEs focus on the purpose and goals of the research in hand. This is because an SMEs in USA may be large enterprise in India, and possibly a very large enterprise in Tanzania (Nyamanza, 2019). The Organization for Economic Cooperation and Development (OECD) and the USA Chamber of Commerce designate a small business as any firm employing fewer than 100 people. By European standards, a small business is one with less than 50 employees, and a medium size one employs between 50 and 100 people (Mahemba and Bruijn, 2003). In Tanzania, most studies that have been conducted use the number of employees as the basis of a definition (Anderson, 2011; Mbura, 2008; Isaga, 2012; Nyamanza, 2019). Also, Nyiti (2001) defines an SME based on the number of employees, with micro (1 to 4), small (5 to 49), medium (50 to 99), and large firms (more than 100). Apparently, a new definition of SMEs in Tanzania represents micro, small and medium enterprises (URT, 2003). This definition was established to include the number of employees, capital invested and turn overs as illustrated in table 1 below. This arises from the facts that the number of people employed alone may not be a good indicator especially if the industry is labor intensive (URT, 2012). The study claims that in some cases trading organization can transact huge sums of business worth transactions and yet they employ few people.

Table 1. Categories of SMEs in Tanzania

\begin{tabular}{|c|c|c|c|}
\hline $\begin{array}{l}\text { Category of } \\
\text { enterprises }\end{array}$ & Number of employees & $\begin{array}{l}\text { Capital invested (Tshs) in } \\
\text { millions }\end{array}$ & Turnover (Tshs) in millions \\
\hline Micro & 1- 4 & Up to 5.0 & 12.0 \\
\hline Small & $5-50$ & $5.1-200.0$ & 150.0 \\
\hline Medium & $51-100$ & $201-800.0$ & 300.0 \\
\hline Large & 101\& above & Above 800.0 & Above 300.0 \\
\hline
\end{tabular}

Source: URT (2003); 1US\$ is equivalent to 2,310 Tanzanian Shillings in 2021.

This paper takes the above position in defining SMEs and would include all such business activities that fulfill the conditions that: SMEs must be formally registered with Business Registrations and Licensing Agency (BRELA) and also listed in the data base of Small Industries and Development Organization (SIDO). Further, the nature of business activities should be in the manufacturing industry; and the number of employees include the working business owner/managers; and when an enterprise falls under more 


\section{The Importance of Marketing Research Practices on the Performance of Tanzanian Manufacturing SMEs.}

than one category i.e. one employee but capital investment is greater than 5 million Tanzanian shillings; then the level of capital investment is the deciding factor in determining the size category.

\subsubsection{Characteristics and challenges of SMEs in Tanzania}

SMEs in Tanzania facilitates distribution of economic activities within the economy and hence contributes to increased participation of indigenous Tanzanian in the economic activities, which in turn foster equitable income distribution. According to Nyamanza (2019), SMEs have a great potential to complement large industries requirements through business linkages, partnership and subcontracting relationships. Accordingly, Tanzanian SMEs absolutely possess the following characteristics:

1. They operate in dynamic and competitive markets, which reveal the reason why they have a tough time in the globalized market.

2. SMEs in Tanzania are vividly confronted with limited manpower in relation to their counterparts in the developing economy and most SMEs are owner operated. This means they deal directly with customers and maintains close relationships with them.

3. SMEs in Tanzania have simple structures and are generally small. Due to their smallness, they are said to have limited access to financial resources and poor internal capabilities to make effective entrepreneurial transition largely due to their inability to borrow to fund high risk projects (Mahemba, 2003; Mbura, 2008).

4. They also have small market share as they use simple technology (Olomi, 2006) and thus they are facing barriers from global sourcing.

5. Isaga (2012) maintains that although SMEs owner(s) in Tanzania seem to have high commitment, stable and long term thinking perspective, they are faced with difficulties to adapt corporate culture to new situations and challenges. Further, they are challenged with limited experiences and low education level. Anderson (2012) calls this lack of management expertise.

6. SMEs' revenue is generally lower than companies that operate on a larger scale. Therefore, one of the major problems facing SMEs result from their size and newness (Mdasha et al., 2018).

7. SMEs in Tanzania serve a much smaller area than larger businesses. The smallest-scale businesses serve single communities such as a convenience store in a rural township since growing beyond that would increase the scale of small business operations and push it in a new classification. In support of this, Isaga (2012) reveal that SMEs sector in Tanzania is largely dominated by sole proprietors (75\%) and are found to be concentrated in certain trades such as restaurants and hotels (51.8\%); manufacturing (24\%), street food vending (11\%); and urban agriculture (10\%). Besides, most of them $(70 \%)$ are not formally registered with the majority of owner-managers possessing limited formal education and training; which translates into a very low level of innovative character. In brief, SMEs face other challenges like regulatory constraints stemming from the difficulty of obtaining legal status. Olomi (2006) calls this poor enabling environment because the institutions supporting them are weak in Tanzania, and their services mainly focus on helping the poor to survive.

\subsection{Marketing Theories}

Several theories have been generated and try to narrate the concept of marketing as a process and market access. This study intends to review three of the theories with the view of understanding key marketing factors that relate to SMEs market access and growth. The theories provide a conceptual framework to explain the differences in the influence of the marketing functions. Market orientation theory holds that the key to achieving organisational goals is being more effective than competitors in integrating marketing activities to determine the needs of target markets (Kotler, 2001; Buli, 2017). But developing a market orientation is not the same as developing a marketing orientation (Baines et al., 2011). The theory insists that a company with marketing orientation would be a company that increases the importance of marketing within the organisation, e.g. by appointing a marketing person to its board of directors, or trustees in the case of a charity or part of the executive team in a limited company or partnership. On the contrary, developing a market orientation, refers to the organisation-wide generation of market intelligence pertaining to current and future customer needs, dissemination of the intelligence across the departments, and organisation-wide responsiveness to it (Ogbu, 2017; Resnick et al., 2016).).

Therefore, a market orientation is more than just getting involved in marketing, rather it involves all facets of a business company, collecting, analysing and reacting to market intelligence. Firms with better understanding of their customers, competitors, and environment have a better market sensing and competitive edge (Buli, 2017). Enterprises should strive to understand customer needs which should then be translated into products. To this end, market research and consumer analysis are important tools to enable firms gather the right information to effectively market its products and meet customer needs competitively (Kiveu and Ofafa, 2013). Undoubtedly, other group of scholars went as far as mentioning that there is a positive relationship between market orientation and firm performance (Baines et al., 2011; Shirazi, 2017; Kotler et al., 2010). Closely linked to market orientation theory is the evolutionary systems change theory, which argues that the ability of a firm to survive and succeed depends upon its ability to search for and respond to the needs of the market niches. However, market systems are dynamic, changing in response to evolving needs and the behaviour of competitors; making the market system to be in a continuous shift towards disequilibrium. Firm thus need to adapt to the new environment and achieve a competitive edge through improvements, maintaining high quality, selecting strategic market sites, promoting product and services, identifying niche markets and access other markets outside their localities (Kiveu and Ofafa, 2013). 


\section{The Importance of Marketing Research Practices on the Performance of Tanzanian Manufacturing SMEs.}

Notwithstanding, the contingency approach acknowledges that various factors affect the small firm's marketing performance and that there is no universal set of strategic choices that is optimal for all businesses regardless of their resources or environment in which they operate. The contingency approach is positioned between two extreme views which state that universal marketing principles exist and are applicable to all firms, or that each small firm is unique and each situation needs to be analysed separately (Mahemba, 2003). This confirms that there is no grand unifying theory; the marketing concepts may be the same but the process of implementation is different in each firm (Kiveu and Ofafa, 2013). The above reviewed marketing theories give insight to the study and will therefore be tested on the marketing research practices in order to determine their potential effects conferred to SMEs performance

\subsection{Conceptual model}

Miles and Huberman (1994) note that the conceptual framework serves a several purposes, some of which include: (a) identifying who will and will not be included in the study; (b) describing what relationships may be present based on logic, theory and/or experience; and (c) providing the researcher with the opportunity to gather general constructs into intellectual "bins". They insist that the conceptual framework serves as an anchor for the study and is referred at the stage of data interpretation.

This study proposes a model of the importance of marketing research on the performance of SMEs in Tanzania. As shown in figure 1 , the model has three major components namely: marketing research practices, performance (outcomes), and the internal environment (operational capabilities) of a firm. In this case, numerous factors are in a position to affect SMEs performance and marketing research is perceived to be the last link in the chain of factors determining patronage and therefore, firm performance. Among the factors affecting SMEs performance are firm's resources in terms of both financial and human resources (operational capabilities) of an individual firm (Buli, 2017); marketing research processes (Nyamanza, 2019); as well as wider macro business environment (Mdasha et al., 2018; Ghouri et al., 2011). Therefore, the study focuses on marketing research practices because most of the other factors that influence firm's performance can equally be used as strategies for marketing.

Ideally, four independent variables of marketing research which are significant from Tanzanian manufacturing business perspective will be observed and examined and their effects on dependent variable are to be investigated. For SMEs' marketing research practices, the listed factors affecting performance are categorized as degree of importance attached to marketing research, types of marketing research performed, Usage of marketing research information generated by external agents, and amounts of research reports produced. The dependent variable is SMEs performance measured in terms of increased sales volume, profitability, and increased number of employees. Variables are selected from the available literatures and theories for building a framework and analyze the results. Likewise, a number of past empirical studies that have adopted both the subjective and objective concepts in the measuring of performance reported a strong association between the objective and subjective measures (Mahemba, 2003; Isaga, 2012; Oyedijo et al., 2012).

The theoretical model below assumes that some business environmental factors are beyond the firm's control, the SMEs can, by adjusting the focus of its marketing research strategies, continue to increase its performance levels irrespective the state of its operating environment. Subsequently, the model appreciates the existence of other moderating factors from the wider-macroeconomic environment and from within the SMEs itself. This is in line with Fu (2011) who postulates that environment moderates the effectiveness of organizational characteristics. However, these issues are outside the focus of the current study. The research model below highlights the constructs and hypothesized relationship in the study.

Figure 1: A theoretical model for the interplay of marketing research dimensions and environmental factors on the SMEs performance of the Tanzanian manufacturing sector.

\section{IV: Marketing research practices/strategies}

1. Types /approaches of marketing research performed or used

2. Utilisation of marketing research information gathered through external/outside agents

3. Degree of importance attached to marketing research

4. Amounts/number of marketing research reports produced for SMEs

\section{MV: Wider macro environment}

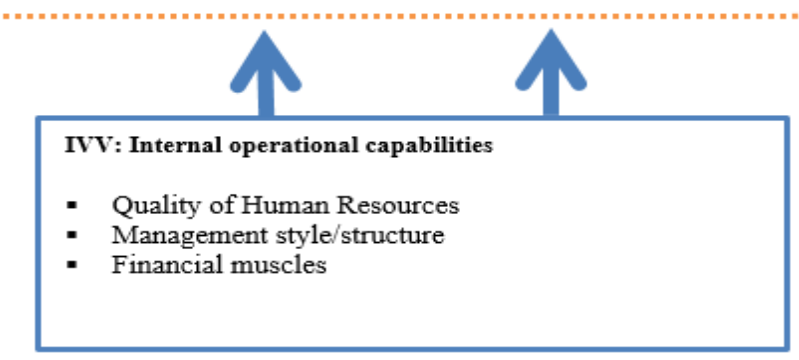

Note: the dotted portions are the areas of interest to this study

Source: Researcher's conceptual lens 


\section{The Importance of Marketing Research Practices on the Performance of Tanzanian Manufacturing SMEs.}

\subsection{Hypotheses formulation}

In this study, hypotheses are developed based on the objectives, and critical review of the existing theories while taking into consideration the hypothesized relationship in the conceptual framework depicted above. Since SMEs are facing more pressure and market challenges than ever; then, their effectiveness will amongst others depend on the ability to respond to the changes taking place in the market (de Waal, 2012). They need to gather information on competitors' activities and redesign their strategies for business growth (Fu, 2011). Consequently, marketing research activities performed within the Tanzanian manufacturing SMEs are expected to result in an improved performance and hence, the following three hypotheses are proposed:

1. There is no significant difference in the growth of Tanzanian manufacturing SMEs and marketing research approach used being formal or informal.

2. The extent to which marketing research information gathered through external agents is utilized in the Tanzanian manufacturing SMEs affect positively their levels of growth.

3. The extent of marketing research practices executed positively affects the growth of Tanzanian manufacturing SMEs .

\section{METHODOLOGY}

The study employed a quantitative method in which a cross-sectional analytical survey design was used with the view to examine the importance of marketing research on SMEs performance in the manufacturing sector. The cross-sectional survey design is preferred over longitudinal study because it allows flexibility in terms of time, financial constraints, and avoiding the hardship of hunting for respondents more than once to produce high response rate (Bryman and Bell, 2011).

The study was carried out in Dar es Salaam region and according to Small Industries Development Organizations (SIDO) data base (Table 2); there are 1326 formally registered manufacturing small and medium scale enterprises in the city of Dar es Salaam. So, simple random sampling procedure was adopted and 200 SMEs were selected. A semi-structured questionnaire with few openended questions were designed in order to obtain primary information and to allow owner-managers of SMEs to express and give some details of their feelings about the subject in question. The survey instrument utilised for the study reflected the framework depicted in figure 1 as it covers all the research concepts. This way, the questions to the key constructs were derived from past survey instruments as well as extant literature with modification to suit the model requirements. Items used in the measurement of marketing research activities were adapted from Jayashankar (2013) and Aziz and Yasin (2010). To measure performance of SMEs, items were drawn from Mahemba (2003); Isaga (2012); and Nyamanza (2019).

In as far as sampling unit is concerned, two-stage process was used. First the sample unit is represented by the individual firm selected, and then the second stage focuses on the individuals within that firm who should be the subject of attention. This way, the unit of analysis was at the organisational level in which, the SMEs owner-managers were chosen from the respective firms depending on who is an in charge of the firms' activities and the easy of accessibility. These were chosen because they were perceived to have the required knowledge and experience of the SMEs' day-to-day management.

Being the largest commercial city in Tanzania, Dar es Salaam has the largest number of small and medium enterprises (URT, 2009) and this is reinforced by the fact that the purchasing power of Dar es Salaam residents is high compared with other regions in Tanzania, and thus provides a good ground for carrying out this study in the city (Mdasha et al., 2018). Here again, SMEs employing between 5-100 employees and an annual turnover of less or equal to 300 million of Tanzanian shillings (US\$ 150,000) were selected because they were thought to have their records available with the sampling frame than it would be with the micro firms. This facilitated in locating them as most of them were well-known in their locality. Experience drawn from Olomi (2001) who included micro enterprises in his study shows that there were problems in locating the availability and location of the SMEs in the existing sampling frame, and so he had to adjust random sampling to 'snow-ball' kind of approach due to lack of proper records on the location and firms' availability. We thought the problem would be more acute within the manufacturing micro enterprises.

Table 2: Population and Sampling decision

\begin{tabular}{lll}
\hline Region & Total Population of manufacturing SMEs & Sample size selected \\
\hline Dar es Salaam & 1326 & 200 \\
Total & 1326 & 200 \\
\hline
\end{tabular}

Source: Small Industries Development Organisation (SIDO), 2016

Statistically, in order for generalisation to take place, a sample of at least 30 must exist (Hair, Black, Babin, Anderson, and Tatham, 2006). Other scholars suggest the use of rule of thumb in selecting a sample that will enable the use of strong statistical analyses such as multiple regression. The simplest rule states that $\mathbf{N} \geq \mathbf{5 0}+\mathbf{8 m}$ where $\mathbf{m}$ is the number of independent variables and $\mathbf{N}$ is 


\section{The Importance of Marketing Research Practices on the Performance of Tanzanian Manufacturing SMEs.}

the number of cases. Given our 4 independent variables, the size of the sample meeting this criterion should be $50+8(4)=82$. The second rule of thumb requires that $\mathbf{N} \geq \mathbf{1 0 4}+\mathbf{m}$. Translating this rule into our data we arrive at a sample of $(104+4)=108$. We think these provide the minimum requirements of the sample size because the literature suggests that larger samples have the effect of increasing the statistical power by minimising errors (Hair et al., 2006).

The process of data collection started in December 2020 through February 2021. The first part of the survey instrument was devoted to the general information and individual characteristics. The second part was concerned with the firms' internal and operational capabilities. The third part asked information on the marketing research practices of SMEs. Subsequently, the fourth part asked information relating with business performance. What's more, the questionnaire had clear, simple and unambiguous questions. These questions were preceded by overall instructions to the respondents on the objectives of the study and the reasons why they have been chosen to participate. This is motivated by Blumberg, Cooper, and Schindler (2011) who posit that questionnaire with a set of details but clear is easy to complete correctly.

Prior to the use of the questionnaire, a pilot study was undertaken to pre-test the questionnaire. A pre-test of the instrument was conducted on 10 SMEs owner-managers in order to ensure clarity and validity of the survey instrument (expert opinion method). These SMEs were conveniently sampled based on the geographic proximity and ease of personal contact because statistical methods are not necessary in the pilot study (Mbura, 2008). In this regard, some minor changes were made to produce a final version. The significance of carrying out a pilot study is often emphasised in the literatures (Blumberg et al., 2011). Reliability of the questionnaire was assessed using the Cronbach alpha statistic. The Cronbach's test of reliability was used because it has the most utility for multi-item scales at the interval level measurement (Cooper and Schindler, 2003; Mbura, 2008) and it counteracts many of the weaknesses of both the split half reliability test and the test retest reliability. Usually, the level of attention and consideration given to issues pertaining to reliability and validity determines the quality of any research work (Oyedijo et al., 2012). Notably, the proposed level of reliability to be used is normally 0.70 (Mbamba, 2003). Other writers however, accept slightly lower level of reliability (Mbura, 2008; Nyamanza, 2019).

Further, to ensure the relevance of the questions the translation of questionnaire from English into Swahili language was done and approved by the National Kiswahili Council although only $10 \%$ of the respondents had shown an interest in the Swahili version. Also, a need for having interviewer-administered semi structured questionnaire was realised instead of using self-administered one (Cooper and Schindler, 2003). This method has also been credited for ensuring objective response and reduced non-response rate. The response rate was actually $100 \%$ despite some delays from few respondents. In checking data normality, the study adopted the rule of thumb that kurtosis greater than 10.0 and univariate skew values greater than 3.0 may be suggestive of problem of data normality (Hair et al., 2006). Literature also suggests that when variables are extremely skewed, factor analysis should not be used (Oyedijo et al., 2012). The results from this research were far below these abnormality values. Besides, the findings were cleared from multicollinearity problem since a maximum acceptable Variance Inflation Factor (VIF) according to Hair et al. (2006) is up to a level of 10.0 .

By using a computer, data preparation and analysis was executed through the statistical analysis software known as SPSS:21 at $95 \%$ confidence level or better with the view to get the most out of power of the tests. This conforms to other scholars (Blumberg et al., 2011; Bryman and Bell, 2011) who propose that, the choice of statistical test depends on the power of statistical analysis, the manner in which the sampled data was drawn, the nature of the population, the particular hypotheses to be tested, and the kind of measurement or scale of the variables. Finally, data analysis results are presented through descriptive statistics, Chi-square and cross-tabulation tests, Spearman rank-order correlation, Independent sample t-Tests; and regression analysis tables here below.

\section{RESULTS AND DISCUSSION}

Since the focus of this research centred around two major constructs namely: the marketing research practices, and SMEs performance then we now present the results and discussion along these themes and constructs.

\subsection{Descriptive summaries}

The 200 SMEs surveyed were grouped into twelve general categories of industries within the manufacturing sector and the results (Table 3) indicate that the largest group of the SMEs were involved in wood making (38.5\%), food processing (14.5\%), and concrete or blocks making (13\%). Other businesses were fabricated metal products (12\%); plastics (5\%); chemical products $(4.5 \%)$; beverages (3.5\%); textile (3\%) as well as Leather (2.5\%). The smallest groups were SMEs specialising in paper products (1.5\%); other building and finishing materials $(1.5 \%)$; as well as electrical materials $(0.5 \%)$. This suggests the type and nature of businesses which are common to small manufacturing firms in Tanzania and it compares well with the work of other scholars (Mahemba, 2003; Mbura, 2008, Isaga, 2012, Olomi, 2006; Isaga, Masurel and Montfort, 2015). 


\section{The Importance of Marketing Research Practices on the Performance of Tanzanian Manufacturing SMEs.}

Next, more than a half of manufacturing SMEs interviewed (57\%) had less than five years of business experience, while $23 \%$ were between 6 and 10 years of business experience. In total, about $80 \%$ of the SMEs interviewed were in business for ten years or less, and the rest ( $20 \%$ of SMEs) were established for more than ten years. This signifies that many manufacturing firms are still at the infancy stage of their development and could be a result of recent government efforts and initiatives in fostering the Sustainable Industrial Development Policy of 1996, and SMEs development policy of 2003. It can further be related to the crowning of trade liberalisation of 1986 and introduction of free-market economy in the 1990s in Tanzania.

The biographical data of the respondents indicated that the majority of them had completed primary level and secondary ordinary level education with $26 \%$ and $20 \%$ respectively making a total of $46 \%$ in these categories. Few of the respondents (12\%) had attained secondary advanced level education or vocational training. Further, SMEs owners/managers who had either professional or University education accounts for $37 \%$. This is not surprising in Tanzania because other studies have found similar results suggesting that typically most SMEs are owned by people with low levels of education (Mahemba, 2003; Mbura, 2008; Isaga, 2012; Isaga et al., 2015; Anderson, 2012). This is possibly because most of the people with better education have a wider choice of occupation. Olomi (1999) insists that less well-educated people in developing countries find it difficult to secure paid jobs and are therefore forced to opt for self-employment as an alternative for development and their survival. Alternatively, it could also mean that the Tanzanian manufacturing sector is apparently improving to become an attractive niche for the educated class due to globalisation and technological shift.

Table 3: Demographic profile of sampled Manufacturing SMEs

\begin{tabular}{|c|c|c|}
\hline & Frequency (No. of SMEs) & Percent \\
\hline \multicolumn{3}{|c|}{ Business experience (No. of years SMEs in business) } \\
\hline Less than 5 years ago & 114 & 57.0 \\
\hline $6-10$ years ago & 46 & 23.0 \\
\hline $11-15$ years ago & 18 & 9.0 \\
\hline $16-20$ years ago & 8 & 4.0 \\
\hline Over twenty years & 14 & 7.0 \\
\hline Total & 200 & 100.0 \\
\hline \multicolumn{3}{|l|}{ Type of industry } \\
\hline Textile & 5 & 2.5 \\
\hline Paper products & 3 & 1.5 \\
\hline Beverages & 7 & 3.5 \\
\hline Wood & 77 & 38.5 \\
\hline Food & 29 & 14.5 \\
\hline Chemical products & 9 & 4.5 \\
\hline Plastics & 10 & 5.0 \\
\hline Fabricated metal products & 19 & 9.5 \\
\hline Concretes or Blocks & 26 & 13.0 \\
\hline Fabricated Aluminium products & 5 & 2.5 \\
\hline Hospital and Laboratory products & 1 & .5 \\
\hline Other building and finishing materials & 3 & 1.5 \\
\hline Electrical materials & 1 & .5 \\
\hline Leather and leather materials & 5 & 2.5 \\
\hline Total & 200 & 100.0 \\
\hline \multicolumn{3}{|l|}{ Legal Form of business } \\
\hline Sole proprietorship & 117 & 58.5 \\
\hline Partnership $^{1}$ & 48 & 24.0 \\
\hline Incorporated company & 24 & 12.0 \\
\hline Registered branch of an overseas company & 9 & 4.5 \\
\hline Joint venture & 2 & 1.0 \\
\hline Total & 200 & 100.0 \\
\hline \multicolumn{3}{|l|}{ Gender of respondents } \\
\hline Male & 162 & 81.0 \\
\hline
\end{tabular}

${ }^{1}$ Partnership business in Tanzania is defined as “... the relationship that subsists between persons carrying on a business in common with a view to profit making; and each of these persons is called a partner. The partnership business may be a temporary partnership or permanent partnership; and the membership is between two to a maximum of twenty. However, legally for a professional service the number may be up to fifty if each of the partners is a qualified person e.g. accountants.

JEFMS, Volume 4 Issue 5 May 2021 
The Importance of Marketing Research Practices on the Performance of Tanzanian Manufacturing SMEs.

\begin{tabular}{|l|l|l|}
\hline Female & 38 & 19.0 \\
\hline Total & $\mathbf{2 0 0}$ & $\mathbf{1 0 0 . 0}$ \\
\hline Completed level of formal education & & \\
\hline No formal education & 10 & 5.0 \\
\hline Primary School & 52 & 26.0 \\
\hline Secondary (O-level) & 40 & 20.0 \\
\hline Secondary (A - level) & 11 & 5.5 \\
\hline Vocational Trainings & 13 & 6.5 \\
\hline Professional (e.g. CPA, Diploma, ACCA, etc.) & 30 & 15.0 \\
\hline University degree & 34 & 17.0 \\
\hline Master's degree/PhD & 10 & 5.0 \\
\hline Total & $\mathbf{2 0 0}$ & $\mathbf{1 0 0 . 0}$ \\
\hline
\end{tabular}

Source: Survey Findings, 2020

Additionally, SMEs surveyed were grouped according to their legal form of business. In Tanzania, a business can be registered in any one of the following five legal forms namely: sole proprietor, partnership, incorporated company, joint venture, and a registered branch of overseas company (TCCIA, 1995). The sample results indicate that a large proportion of the SMEs studied were sole proprietors, followed by partnership business, and when combined they represent over $82 \%$ of the sampled manufacturing SMEs. The smallest groups identified were overseas companies having branches in Tanzania and joint venture, who had only $4.5 \%$ and $1 \%$ of the total sample respectively. This indicates that there are very few overseas SMEs and joint venture businesses doing business in the manufacturing sector in Tanzania possibly due to unfavourable business and legal conditions for foreign companies.

Despite the fact that women constitute the majority of the population in Tanzania (Rutashobya, 2001; URT, 2012) men continue to dominate in the ownership of business. Apparently, 81\% of the sampled SMEs owner-managers were male and the rest (19\%) were female. A small number of female managers/owners of SMEs in Tanzania may be due to normative and cultural beliefs about a woman's role in Tanzanian society; or else it may be because of the fact that the business environment is not accommodating to female entrepreneurs or managers. Rutashobya (2001) goes as far as arguing that some of the fundamental factors that constrain women's strategic choices in respect of the type of business undertaken include their multiple productive and reproductive roles in the society.

The status of those who manage the SMEs was also examined and the findings show that most of the SMEs are owned and managed by owners themselves. About $44.5 \%$ of all respondents were owners who also managed the firms; whereas $41 \%$ of the respondents managed the businesses which were not theirs. The rest, $14.5 \%$ of all the respondents were owners who did not manage the firms but most likely, they kept an eye on their ventures and corresponding operational activities by employing employee-managers. This probably explains the reason as to why they volunteered to spare time for the interviews as they were considered the most informed about the firms' operations.

Figure 2: Titles and positions in the business firm

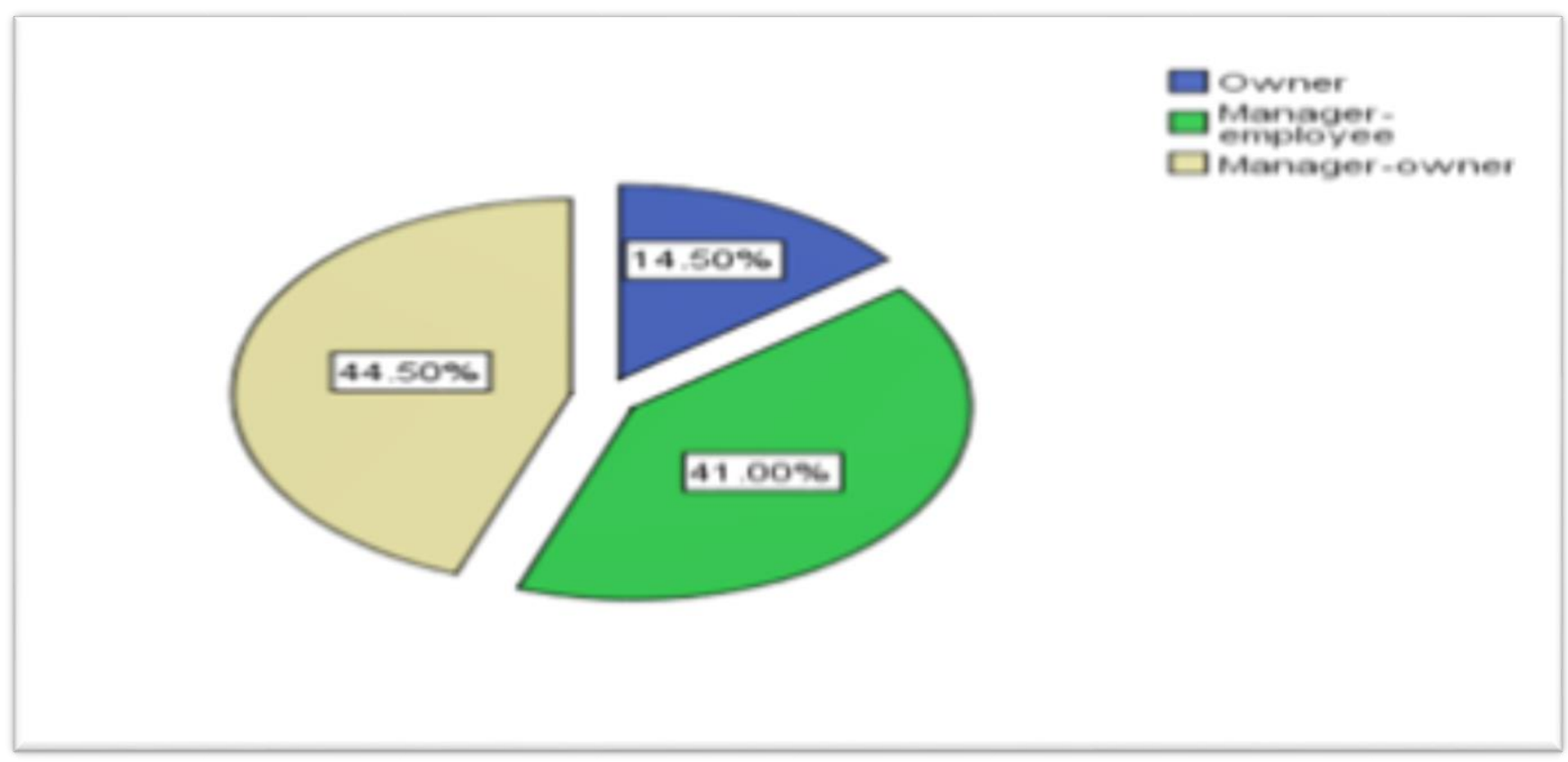

Source: Field findings, 2020 


\section{The Importance of Marketing Research Practices on the Performance of Tanzanian Manufacturing SMEs.}

\subsection{Correlation Analysis and Hypothesis testing}

The objective of the study is to establish the predictive ability of the marketing research variable(s) to the performance of manufacturing SMEs with the view to be able to conclude whether or not marketing research activities are effective in increasing the growth of SMEs and to explore the extent to which SMEs growth are affected by those marketing practices. These objectives are achieved through carrying out the reliability, correlations, chi-square tests; independent sample t-tests, and regression analysis and finally testing the hypotheses. As pointed earlier, Table 4. Shows the reliability analysis (Cronbach alpha) of the research measures of marketing practices and their performance. Both values exceeded the recommended minimum in the extant literature (Hair et al., 2006). Accordingly, Mbamba (2003) proposes that the level of reliability to be used is normally 0.70 .

Table 4. Reliability Coefficient of research measures in a current study

\begin{tabular}{|l|l|l|}
\hline Type of construct(s) & Number of items & Cronbach's Alpha Coefficient \\
\hline Growth performance indicators & 8 & 0.7 \\
\hline Firm's internal environment & 26 & 0.87 \\
\hline Marketing Research practices & 12 & 0.77 \\
\hline
\end{tabular}

Source: Research findings, 2020

As far as Correlations Analyses are concerned, the correlation coefficient [Spearman Correlation ( $\left.r_{s}\right)$ ] was used to assess this relationship as the majority of data were gathered from a non-metric scale (ranked data) which is the best for our study (Cooper and Schindler, 2003); and those few interval/ratio scales were converted into ranks before calculating spearman's correlation. It only measures the strength of the linear relationship between two variables. Arguably, the Correlation coefficient measured in terms of both Pearson Correlation and Spearman Correlation are very similar and are interpreted in the same way except that the two approaches use different measurements or formula to calculate the strength of association. According to (Bryman and Bell, 2011)) it is extremely unusual to obtain perfect correlations within business research. This view is supported by Royse (2003) who asserts that correlations as high as 0.70 are rare particularly in social science research where they are typically 0.40 or less. However, what matters more is the level of significance. The guidelines are that to be statistically significant, the probability should be at most 0.05 . This means that in order to reject the null hypotheses there must be fewer than 5 chances in one hundred that you will be wrong (Hair et al., 2006). In some cases, a lower level of less than 0.10 is considered acceptable. But to accept this probability level brings about more risk and the analyst must decide if the situation warrants higher risk.

Twelve items were used to capture information regarding the marketing research practices and were grouped into four categories (Figure 1). Table 5. Reveals the Correlation matrix for the four dimensions, namely: degree of importance attached to marketing research, types/approaches of marketing research used within SMEs, utilisation of marketing research information from outside agents; and amounts/number of marketing research reports produced in a year. These variables were in the first place converted into median through Median function transformation process. This method returns the median $\left(50^{\text {th }}\right.$ percentile) of its arguments that have valid non-missing values. The point of concern here was to examine whether marketing research activities of a firm correlates with the SMEs growth construct(s) captured at a metric scale. Therefore, the Pearson's Correlation was used to test the data from the 200 respondents and reveals that most of the independent items have positive moderate relationship, and are significantly correlated at 0.01 and 0.05 levels of significance. This way, a strong basis for further robust analysis is established.

Nevertheless, the correlations between utilisation of marketing research information from outside agents and the change in the number of employees $\left(r_{s}=0.006\right)$; as well as degree of importance attached to marketing research versus percentage changes in profits $\left(r_{s}=0.050\right)$; reveal some positive relationships; but such relationships are said to be statistically very low and insignificant. In short, the majority of these items fairly correlated and the overall trend provides adequate basis for proceeding (logical to continue) with further robust analysis.

Table 5. Correlations output for Marketing research variables and SMEs growth construct(s)

\begin{tabular}{|l|l|l|l|l|}
\hline \multicolumn{2}{|l|}{$\begin{array}{l}\text { Marketing research } \\
\text { Variables Spearman's rho }\end{array}$} & $\begin{array}{l}\text { Percentage changes } \\
\text { in Sales turn-over }\end{array}$ & $\begin{array}{l}\text { Change in the } \\
\text { Number } \\
\text { employees }\end{array}$ & $\begin{array}{l}\text { Percentage } \\
\text { of } \\
\text { changes } \\
\text { business profits }\end{array}$ \\
\hline \multirow{2}{*}{$\begin{array}{l}\text { utilising market information } \\
\text { gathered through outside agents }\end{array}$} & Correlation Coefficient & $\mathbf{. 2 9 8 ^ { * * }}$ & $\mathbf{. 0 0 6}$ & $\mathbf{. 3 0 5}^{* *}$ \\
\cline { 2 - 6 } & Sig. (2-tailed) & .000 & .934 & .000 \\
\cline { 2 - 5 } & $\mathrm{N}$ & 200 & 200 & 200 \\
\hline & Correlation Coefficient & $\mathbf{. 1 2 1}^{* *}$ & $\mathbf{. 2 1 2 ^ { * }}$ & $\mathbf{. 0 5 0}$ \\
\hline
\end{tabular}


The Importance of Marketing Research Practices on the Performance of Tanzanian Manufacturing SMEs.

\begin{tabular}{|c|c|c|c|c|}
\hline \multirow{2}{*}{$\begin{array}{l}\text { Degree of importance attached } \\
\text { to Marketing Research }\end{array}$} & Sig. (2-tailed) & .007 & .016 & .482 \\
\hline & $\mathrm{N}$ & 200 & 200 & 200 \\
\hline \multirow{3}{*}{$\begin{array}{l}\text { Number of marketing research } \\
\text { reports produced }\end{array}$} & Correlation Coefficient & $.211^{* *}$ & $.184^{* *}$ & $.164^{* *}$ \\
\hline & Sig. (2-tailed) & .003 & .009 & .004 \\
\hline & $\mathrm{N}$ & 200 & 200 & 200 \\
\hline \multirow{3}{*}{$\begin{array}{l}\text { Types/approaches of marketing } \\
\text { research performed (used) }\end{array}$} & Correlation Coefficient & $.179^{*}$ & $.256^{* *}$ & $.362^{* *}$ \\
\hline & Sig. (2-tailed) & .011 & .000 & .000 \\
\hline & $\mathrm{N}$ & 200 & 200 & 200 \\
\hline
\end{tabular}

** Correlation is significant at the 0.01 level (2-tailed).

* Correlation is significant at the 0.05 level (2-tailed).

Source: Research findings, 2020

\subsubsection{Marketing research approach and SMEs performance}

The manufacturing sector in Tanzania, among others, is heavily challenged by both internal and external environment, which in the authors' view, requires that they must constantly analyse the business environment, develop effective strategies that suits the current global trends, and brings on the table solutions to customers in order to remain in a competitive posture (Nyamanza, 2019). SMEs need to practice effective marketing programs which depends on marketing research orientations so as to effectively induce customers and increase sales or profits.

In lieu of this, marketing research practices of SMEs is considered as an important predictor of SMEs growth although the sample results indicate that the majority of Tanzanian manufacturing SMEs (66.5\%) do not use structured marketing research as shown in Table 4.4. It is tempting to argue that the majority of SMEs do not include marketing research practices as one of the tools for making formal decisions, in spite of being managed and run by (49\%) personnel who possess advanced secondary or professional and University education. In addition, about $12 \%$ and $4.5 \%$ were SMEs registered as both incorporated companies and branch of an overseas companies respectively and yet, in its overall, the marketing processes that they undertake are seen as being informal.

Table 6. Marketing research approach used in the manufacturing SMEs

\begin{tabular}{lcc}
\hline \hline Types /approach of marketing research & Frequency & Percent \\
\hline Unstructured marketing research & 131 & 65.5 \\
Structured marketing research & 69 & 34.5 \\
Total & $\mathbf{2 0 0}$ & $\mathbf{1 0 0 . 0}$ \\
\hline \hline
\end{tabular}

Source: Research findings, 2020

The above observation is supported by the results of other empirical studies (Walsh and Lipinski, 2009; Dragnic, 2009; Isaga et al., 2015) thus, the following hypothesis:

\section{Hypothesis 1}

There is no significant difference in the growth of Tanzanian manufacturing SMEs and marketing research approach used being formal or informal

With regards to the relationship between growth and the marketing research activities of the firms, two criteria were used to determine the extent of growth performance namely: profitability and sales turn-over. In this case a seven-point scale which was originally used to capture information from the respondents had to be reduced to three-point scale during analysis, and the values were re-coded into SPSS: 21 for the second time with the aim of collapsing the initial values to a few ones so as to accommodate the assumptions behind chi-square and cross-tabulation analysis. This was found to be useful in minimising the sampling errors thus indicating a reasonable number of observations in each category. Therefore, new values coded after collapsing the original ones are 1, 3 and 7 which stands for decreased; remained the same; and increased in terms of firm's profits or sales respectively. This scaling approach has been used in several studies to measure growth performance in SMEs and is able to differentiate between good and poor performance (Mahemba, 2003; Isaga, 2012).

The results in this study indicate that SMEs that adopts structured marketing research appear to have recorded an overall increase in profit(s) than those which adopts unstructured marketing research (12.5\% versus $11 \%$ of the total sample). These relationships are presented in Table $7(\mathrm{a})$. 


\section{The Importance of Marketing Research Practices on the Performance of Tanzanian Manufacturing SMEs.}

Further details reveal that, the majority of the sampled SMEs had their performance in terms of profit remained unchanged especially in SMEs with unstructured marketing research as compared to those which had structured marketing research $(49 \%$ versus $21 \%$ ). Similar observation was also noticed with other growth indicators especially sales turn-over whereby an increase in sales were registered in those SMEs which did apply structured marketing research as compared to those which did not use structured marketing research i.e. $15 \%$ versus $8.5 \%$ (see Table 7.b). This observation matches with the findings from other marketing literature in which organisations lacking a strategic marketing direction do not seem to be competitive in the market and finally fail to survive (Tzokas, Carter, and Kyriazopoulos, 2001). But, is contrary to the work of other researchers who found that formal strategic planning systems do not always provide superior performance (Siu et al., 2004).

Other noticeable differences were at the decreasing levels of firms' performance where by, the majority of manufacturing SMEs which did not consider marketing research as part of the formal decisions demonstrated high decreasing rates on both profitability and sales turn-over than their counterparts which did consider formal or structured marketing research decisions i.e. 5.5\% versus $1 \%$ (in profits) and $9.5 \%$ versus $2.5 \%$ (in sales turn-over) respectively. Simpson et al. (2006) also deduce that successful SMEs generally makes a greater use marketing research orientation in their activities.

The above findings confirm that although the marketing research activities of Tanzanian manufacturing SMEs can be described as being generally informal and unstructured; still the overall positive growth was recorded in SMEs which applied structured marketing research practices both in terms of profits $(12.5 \%$ against $11 \%)$ and sales turn-overs ( $15 \%$ against $8.5 \%)$. It can be concluded that the majority of manufacturing SMEs do not put emphasize on marketing research activities and these observed differences are statistically significant at 5 percent level (i.e. $X^{2}=10.623 ; 2$ d.f.) for profits as well as (i.e. $X^{2}=23.661 ; 2$ d.f.) for sales turn-overs.

Table 7 (a) Marketing research approach used in SMEs and Business profits

\begin{tabular}{|c|c|c|c|c|}
\hline \multirow{2}{*}{$\begin{array}{l}\text { Business } \\
\text { profits }\end{array}$} & \multicolumn{3}{|c|}{ Marketing research approach used } & \multirow[b]{2}{*}{ Total } \\
\hline & & Unstructured marketing research & Structured marketing research & \\
\hline \multirow[t]{3}{*}{ Decreased } & Count & 11 & 2 & 13 \\
\hline & $\%$ of total & $5.5 \%$ & $1 \%$ & $6.5 \%$ \\
\hline & Expected Count & 8.5 & 4.5 & 13.0 \\
\hline \multirow{3}{*}{$\begin{array}{l}\text { Remained } \\
\text { the same }\end{array}$} & Count & 98 & 42 & 140 \\
\hline & $\%$ of total & $49 \%$ & $21 \%$ & $70 \%$ \\
\hline & Expected Count & 91.7 & 48.3 & 140.0 \\
\hline \multirow[t]{3}{*}{ Increased } & Count & 22 & 25 & 47 \\
\hline & $\%$ of total & $11 \%$ & $12.5 \%$ & $23.5 \%$ \\
\hline & Expected Count & 30.8 & 16.2 & 47 \\
\hline \multirow[t]{3}{*}{ Total } & Count & 131 & 69 & 200 \\
\hline & $\%$ of total & $65.5 \%$ & $34.5 \%$ & $100 \%$ \\
\hline & Expected count & 131.0 & 69.0 & 200 \\
\hline
\end{tabular}

Source: Research findings, 2020

Table 7(b) marketing research approach used in SMEs and sales turn-over

\begin{tabular}{|c|c|c|c|c|}
\hline \multirow[b]{2}{*}{$\begin{array}{l}\text { Sales turn- } \\
\text { overs }\end{array}$} & \multicolumn{3}{|c|}{ Marketing research approach used } & \multirow[b]{2}{*}{ Total } \\
\hline & & Unstructured marketing research & Structured marketing research & \\
\hline \multirow[t]{3}{*}{ Decreased } & Count & 19 & 5 & 24 \\
\hline & $\%$ of total & $9.5 \%$ & $2.5 \%$ & $12 \%$ \\
\hline & Expected Count & 15.7 & 8.3 & 24.0 \\
\hline \multirow{3}{*}{$\begin{array}{l}\text { Remained } \\
\text { the same }\end{array}$} & Count & 95 & 34 & 129 \\
\hline & $\%$ of total & $47.5 \%$ & $17 \%$ & $64.5 \%$ \\
\hline & Expected Count & 84.5 & 44.5 & 129.0 \\
\hline \multirow[t]{3}{*}{ Increased } & Count & 17 & 30 & 47 \\
\hline & $\%$ of total & $8.5 \%$ & $15 \%$ & $23.5 \%$ \\
\hline & Expected Count & 30.8 & 16.2 & 47.0 \\
\hline
\end{tabular}


The Importance of Marketing Research Practices on the Performance of Tanzanian Manufacturing SMEs.

\begin{tabular}{|lllll|}
\hline Total & Count & 131 & 69 & 200 \\
\cline { 2 - 5 } & \% of total & $65.5 \%$ & $34.5 \%$ & $100 \%$ \\
\cline { 2 - 5 } & Expected count & 131.0 & 69.0 & 200 \\
\hline
\end{tabular}

Source: Research findings, 2020

Further analysis was carried out to test the hypothesis $\left(\mathrm{H}_{1}\right)$ that there is no significant difference in the growth of Tanzanian manufacturing SMEs and marketing research approach used being structured or unstructured. In this case, an independent $t$-test was performed and the sample results as summarised in Table 8(a) and 8(b) indicate that a significant difference exist at 5\% level with manufacturing SMEs which adopts structured and formal marketing research being more likely to grow. Thus, hypothesis 1 is not supported. This suggests that the critical role of SMEs owner/managers consist of continuous assessment of a firm's performance and evaluation of competitive advantage aimed at seeking improvement and growth. Similar opinions were proposed by Brooksbank (1991) that a successful British SMEs tend to adopt an overall business approach that is marketing oriented, carry out regular and comprehensive situational analyses, have a strategic focus based on increasing sales volume rather than on productivity improvement, show a greater degree of organisational flexibility, and are oriented towards marketing information gathering in control.

\begin{tabular}{|l|l|l|l|l|l|}
\hline \multicolumn{4}{|l|}{ Table 8 (a) Group Statistics for marketing research approach and business profits } \\
\hline $\begin{array}{l}\text { SMEs growth } \\
\text { indicator(s) }\end{array}$ & $\begin{array}{l}\text { Marketing research approach used in the } \\
\text { firm }\end{array}$ & N & Mean & $\begin{array}{l}\text { Std. } \\
\text { Deviation }\end{array}$ & Std. Error Mean \\
\hline $\begin{array}{l}\text { Percentage changes in } \\
\text { profits }\end{array}$ & Unstructured marketing research & 131 & 6.8321 & 15.82848 & 1.38294 \\
\cline { 2 - 7 } & Structured marketing plan & 69 & 21.2029 & 21.42262 & 2.57898 \\
\hline
\end{tabular}

Table 8 (b) Independent Samples Test for marketing research approach and business profits

\begin{tabular}{|c|c|c|c|c|c|c|c|c|c|}
\hline \multirow[t]{3}{*}{$\begin{array}{l}\text { \%age changes } \\
\text { in profits }\end{array}$} & \multicolumn{2}{|c|}{$\begin{array}{l}\text { Levene's Test for } \\
\text { Equality of } \\
\text { Variances }\end{array}$} & \multicolumn{7}{|c|}{ t-test for Equality of Means } \\
\hline & \multirow[t]{2}{*}{$\mathrm{F}$} & \multirow[t]{2}{*}{ Sig. } & \multirow[t]{2}{*}{$\mathrm{t}$} & \multirow[t]{2}{*}{ d.f. } & \multirow[t]{2}{*}{$\begin{array}{l}\text { Sig. } \\
\text { (2-tailed) }\end{array}$} & \multirow[t]{2}{*}{$\begin{array}{l}\text { Mean } \\
\text { Difference }\end{array}$} & \multirow[t]{2}{*}{$\begin{array}{l}\text { Std. Error } \\
\text { Difference }\end{array}$} & \multicolumn{2}{|c|}{$\begin{array}{l}95 \% \text { Confidence Interval of } \\
\text { the Difference }\end{array}$} \\
\hline & & & & & & & & Lower & Upper \\
\hline $\begin{array}{l}\text { Equal } \\
\text { variances } \\
\text { assumed }\end{array}$ & 6.940 & .009 & -5.383 & 198 & .000 & -14.37084 & 2.66966 & -19.63545 & -9.1062 \\
\hline $\begin{array}{l}\text { Equal } \\
\text { variances not } \\
\text { assumed }\end{array}$ & & & -4.911 & 108.1 & .000 & -14.37084 & 2.92637 & -20.17139 & -8.5703 \\
\hline
\end{tabular}

Source: Survey findings, 2020

\subsubsection{Degree of utilizing marketing research information from outside agents and SMEs growth}

In order to test the extent to which SMEs owners/ managers make use of marketing research information from outside agents in their activities, the following hypothesis was formulated:

\section{Hypothesis 2}

The extent to which market research information gathered through outside agents is utilized in the Tanzanian manufacturing SMEs affect positively their levels of growth.

In this context, the sampled SMEs were asked in the survey questionnaire about the extent of use and utilisation of marketing information gathered by outside agents on a five-point scale namely: (i) not at all used, (ii) somewhat used, (iii) used, (iv) often used, ( $v$ ) extremely used. When the responses are received, they were reduced and coded into three main values i.e. some items were combined to generate one level of measurement during the analysis, such that the values were changed into the following: 1 - not at all (retained); 2 - used (combined the scores for somewhat used and used items); and 3 - extremely used (where the scores for very used and extremely used items are combined). The idea behind was to collapse the initial values to a few ones so 


\section{The Importance of Marketing Research Practices on the Performance of Tanzanian Manufacturing SMEs.}

as to accommodate the assumptions behind chi-square and cross-tabulation analysis (Saunders, Lewis, and Thornhill, 2003). This was also useful in producing a reasonable number of observations in each category.

Likewise, the extent of growth (measured in sales turn-over) was captured on a seven-point scale and then the responses, as captured on the scaling items were reduced and combined to formulate a new set of values. The new values coded after collapsing the original ones are: 1, 3 and 7 which stands for decreased (a combination of the scores for decreased and marked decrease items); remained the same (which combines the scores for slight decrease, slight increase, and remained the same items); and increased (a combination of increased and marked increase scores) in terms of firm's sales respectively.

Table 9 below, show that a large proportion of manufacturing SMEs studied (53.5\%) confirm to have used marketing research information from outside agents, followed by $33.5 \%$ who extremely utilised marketing research information from outside agents. When combined they represent about $87 \%$ of the sampled manufacturing SMEs. The rest, $13 \%$ of manufacturing SMEs acknowledged to have never used or utilised marketing research information from outside agents in their activities. But, the majority of the sampled SMEs confirm to have their performance remained the same in terms of sales turn-over (64.5\%) despite the fact that they utilised marketing research information from outside agents at differing proportions.

Noticeably, only (23.5\%) of the SMEs studied indicated to have registered positive growth in terms of sales; and the rest (12\%) declared a slowdown in their performance. This finding suggests that the majority of SMEs utilises external marketing research information possibly due to an increasing pressure posed by competitive business environment and perhaps that small firms find it hard to recruit and retain competent personnel who are capable of producing quality research reports due to company size and resources for business survival. In particular, there is a feeling that performance of manufacturing SMEs would still be effective without the need to do their internal structured marketing research activities.

Table 9. Utilisation of marketing research information from external agents and sales turn-over of SMEs

\begin{tabular}{|c|c|c|c|c|c|}
\hline \multirow{3}{*}{ Sales turn-over } & & \multicolumn{4}{|c|}{ Extent of Utilisation of marketing research info. gathered by } \\
\hline & & \multicolumn{3}{|c|}{ external agents } & \multirow[t]{2}{*}{ Total } \\
\hline & & Not at all & Used & Extremely Used & \\
\hline & Count & 5 & 13 & 6 & 24 \\
\hline \multirow[t]{3}{*}{ Decrease } & Expected Count & 3.1 & 12.8 & 8.0 & 24.0 \\
\hline & $\%$ of total count & $2.5 \%$ & $6.5 \%$ & $3 \%$ & $12 \%$ \\
\hline & Count & 19 & 75 & 35 & 129 \\
\hline \multirow[t]{3}{*}{ Remain the same } & Expected Count & 16.8 & 69.0 & 43.2 & 129.0 \\
\hline & $\%$ of total count & $9.5 \%$ & $37.5 \%$ & $17.5 \%$ & $64.5 \%$ \\
\hline & Count & 2 & 19 & 26 & 47 \\
\hline \multirow[t]{3}{*}{ Increase } & Expected Count & 6.1 & 25.1 & 15.7 & 47.0 \\
\hline & $\%$ of total count & $1 \%$ & $9.5 \%$ & $13 \%$ & $23.5 \%$ \\
\hline & Count & 26 & 107 & 67 & 200 \\
\hline \multirow[t]{2}{*}{ Total } & Expected Count & 26.0 & 107.0 & 67.0 & 200.0 \\
\hline & $\%$ of total count & $13.0 \%$ & $53.5 \%$ & $33.5 \%$ & $100.0 \%$ \\
\hline
\end{tabular}

Source: Survey findings, 2020

Further, the relationship between SMEs performance and the extent to which marketing research information from external agents is utilised was established through chi-square test. This test was chosen due to the nature of categorical data used in this study and to determine if there exist significant relationships between firms' growth level and degree of utilising marketing research information gathered by outside agents. The findings reveal that there are no statistical and significant relationships between the growth performance of manufacturing SMEs and the extent of utilising marketing research data from outside agents at $5 \%$ level of chi-square statistics $\left(X^{2}=14.975 ; 4\right.$ d.f. or $p$-value $\left.=0.005\right)$.

Briefly, SMEs growth performance is not related with the degree of utilising marketing research data gathered by outside agents and thus, hypothesis 2 is not supported. This observation suggests that although marketing research orientation is seen as a key determinant to SMEs success (Sohail and Alashban, 2009; Anderson, 2017; Mdasha et al., 2018) Tanzanian manufacturing SMEs did not seem to pay extra attention and possibly base their success on marketing research information gathered externally as they tend quite often not to formalize them or even rely heavily on personal network with the outside agents who might not be familiar 


\section{The Importance of Marketing Research Practices on the Performance of Tanzanian Manufacturing SMEs.}

with the inward-perspectives of the firm and/or have limited knowledge to produce quality research reports for SMEs. These findings are also in line with the works of other scholars (Tzokas et al., 2001; O'Dwyer et al., 2009) who conclude that the initial stages of any new small business firm, growth usually happens informally with very little attention being paid on planned marketing tasks and henceforth, owner/managers tend to have confidence in the perception that it is unnecessary to invest money, time and efforts in formal marketing efforts. This is opposite to the evidence from Brooksbank et al. (2008) who reveal that a statistically significant relationship at $1 \%$ exists between higher performance and the reported extent of formal marketing research orientation in New Zealand small manufacturing firms. They insisted that organisations with a high level of performance tend to a great extent use their own and internally generated marketing information in the area of market share, product, pricing and distribution techniques compared to the organisations with a low level of performance.

\subsubsection{The extent of implementing Marketing Research tasks and SMEs growth}

Conventionally, it is suggested that one of the roles of marketing is to manage the relationship between business firm(s) and customers, partners and/or the society at large as targets for marketing activity thereby anticipating, identifying, and satisfying customer requirements effectively and profitably (Baines et al., 2011). This idea stresses the importance of considering the customers, and determining their needs. In particular, it recognises the need for marketers and organisations in general to undertake environmental scanning and marketing research activities so as to effectively anticipate customers' needs and satisfy them profitably. Because customers are an important contributor to a firms' performance, the department responsible for management of customer needs and relationships should be viewed as important and influential.

In the literature reviewed (Brooksbank et al., 2008; Anderson, 2017; Panayides, 2004; Baines et al., 2011) indicate that higher performing companies make a greater use of marketing research in their activities. This way, hypothesis 3 is proposed with the view to establish whether the extent of executing marketing research have the same positive impacts on the growth of manufacturing SMEs.

\section{Hypothesis 3}

The extent of marketing research practices executed positively affects the growth of Tanzanian manufacturing SMEs

First of all, to determine whether manufacturing SMEs in Tanzania perceives an implementation of marketing research activities as an important aspect, we asked the SMEs managers/owners to report and provide reflection of their opinions about various marketing research aspects on business growth. So, a five-point Likert-type scales anchored by strongly disagree and strongly agree was used to record the responses and items (1) - number of market reports, and (3) - reports by outside agents were reverse coded (alpha $=0.77$ ). The dependent variables included were percentage changes in sales volume and/or profits for the past three years measured in ratio scale.

The results presented in Table 10 provides descriptive summaries, which suggest that a large proportion of SMEs (69.4\%) perceive marketing research as an important activity. Then, $10.3 \%$ were neutral and thus had nothing to say regarding the importance of marketing research. The rest $(20.3 \%)$ had a negative perception to formal marketing research activities meaning that, some owners and managers of SMEs tend to rely on their personal networks and contacts, and use informal communications in collecting information. In support of this view, Siu et al. (2004) conform that SMEs in Taiwan operate in an "information void" environment in which market survey data seem to be unreliable.

Table 10. Importance of marketing research at SMEs

\begin{tabular}{llll}
\hline \hline Importance of Marketing Research & \multicolumn{2}{l}{ Responses } \\
\cline { 3 - 4 } & Strongly disagree & $\mathrm{N}$ & Percent \\
\hline \multirow{2}{*}{ Disagree } & 31 & $3.1 \%$ \\
& Neither agree nor disagree & 172 & $17.2 \%$ \\
& Agree & 103 & $10.3 \%$ \\
& Strongly agree & 422 & $42.2 \%$ \\
& & 272 & $27.2 \%$ \\
Total & & $\mathbf{1 0 0 0}$ & $\mathbf{1 0 0 . 0 \%}$ \\
\hline \hline
\end{tabular}

Source: Survey findings, 2020

Subsequently, a linear regression was performed and the outputs of this test are shown in Table 11 and 12 respectively. In testing the above hypothesis, the extent of executing marketing research decisions in manufacturing SMEs are examined and was measured using a five-point scales and subjects were evaluated on a phrase "to what extent is...."; and the response format 


\section{The Importance of Marketing Research Practices on the Performance of Tanzanian Manufacturing SMEs.}

stretched from (1) not at all executed to (5) executed to a great extent. Since the sample is not adequate for factor a nalysis (i.e. 200 units), the categorical aspects of marketing research were initially computed and transformed (converted) into median values before a regression analysis is run so that data is reduced into a single set and see if they have adequate explanatory power and robustness. On the other note, the extent of growth was measured in percentage changes in sales turn-over and profits (captured on a ratio scale). Finally, the regression outputs reveal that the extent of executing marketing research activities are on average associated with the changes in sales turn-over by 4.84 points (Table 12). This suggests that the percentage change in sales turnover explained by the model is not due to chance since the regression results reveal a significant value less than 0.05 . Therefore, the proposed model for the degree of executing marketing research and SMEs' growth is statistically significant and so, hypothesis 3 is supported.

However, with an adjusted R-square of 0.029 it means that only $2.9 \%$ of the variance in percentage change in sales turn-over are explained by marketing research efforts on this model. This way, there seem to be close and positive association between the extent of executing marketing research and growth performance of SMEs though not a strong relationship. The results are also similar to the findings of McLarty et al. (2012) who confirm that less values and weight are attached to marketing efforts in the Czech companies and that very few attempts to employ marketing expertise in their operations and do not even collect information about customer's behaviour though marketing is widely acknowledged as the most sensitive factor.

Table 11: Regression output for SMEs growth (\%age change in sales turn-over)

\begin{tabular}{llllllllll}
\hline \hline Model & & Sum of Squares & d.f. & Mean Square & $\mathrm{F}$ & Sig. & $\mathrm{R}$ & $\mathrm{R}^{2}$ & Adjusted R $^{2}$ \\
\hline \multirow{2}{*}{1} & Regression & 4467.187 & 1 & 4467.187 & 6.975 & $.009^{\mathrm{b}}$ & $.184^{\mathrm{a}}$ & .034 & 0.029 \\
& Residual & 126812.168 & 198 & 640.465 & & & & & \\
& Total & 131279.355 & 199 & & & & & & \\
\hline \hline
\end{tabular}

a. Dependent Variable: Sales turn-over percentage changes

b. Predictors: (Constant), Extent of executing marketing research

Table 12. Coefficients dependent variable percentage change in sales turn-over

\begin{tabular}{|c|c|c|c|c|c|c|c|c|c|c|}
\hline \multirow[t]{2}{*}{ Model } & & \multicolumn{2}{|l|}{$\begin{array}{l}\text { Unstandardized } \\
\text { Coefficients }\end{array}$} & $\begin{array}{l}\text { Standardised } \\
\text { Coefficients }\end{array}$ & \multirow[t]{2}{*}{$\mathrm{T}$} & \multirow[t]{2}{*}{ Sig. } & \multirow{2}{*}{$\begin{array}{l}95.0 \% \\
\text { Confidence } \\
\text { Interval for B } \\
\text { Lower Bound }\end{array}$} & \multicolumn{3}{|c|}{ Collinearity Statistics } \\
\hline & & B & $\begin{array}{l}\text { Std. } \\
\text { Error }\end{array}$ & Beta & & & & $\begin{array}{l}\text { Upper } \\
\text { Bound }\end{array}$ & Tolerance & VIF \\
\hline & (Constant) & -3.744 & 6.904 & & -.542 & .588 & -17.358 & 9.870 & & \\
\hline 1 & $\begin{array}{l}\text { Extent of } \\
\text { executing } \\
\text { marketing } \\
\text { research }\end{array}$ & $\begin{array}{l}\text { f } \\
4.844\end{array}$ & 1.834 & .184 & 2.641 & .009 & 1.227 & 8.462 & 1.000 & 1.000 \\
\hline
\end{tabular}

Source: Survey findings, 2020

\section{CONCLUSION}

The main purpose of this study was to explore the marketing research activities of the Tanzanian SMEs and the way they determine SMEs growth potential. This was built on the premise that marketing research is an important function in the organisation and yet there has been little consensus among researchers and professionals concerning the impact marketing orientation has on both international and domestic business operations (Nyamanza, 2019). As the result all the formulated hypotheses were directional in a sense that they all posited positive relationships between the marketing researches constructs and growth indicators. This way, the importance of marketing research for the improved performance of SMEs has been emphasised in this study, in other empirical studies as well as in theories of marketing (see also Tzokas et al., 2001; Kievu and Ofafa, 2013; Buli, 2017). Likewise, findings from this study support the notion that manufacturing SMEs do attach certain importance to marketing research activities though the majority of the sampled SMEs do not use formal marketing research reports in their decisions. It is against this observation that some SMEs owner-managers tend to rely on their personal networks and contacts, and use informal communications in collecting information. 


\section{The Importance of Marketing Research Practices on the Performance of Tanzanian Manufacturing SMEs.}

Accordingly, the study presents some findings that help in clarifying some postulations in the extant literature (Nyamanza, 2019; 2020; Aziz and Yassin, 2010; Oyedijo et al., 2012; Brooksbank et al., 2008) which had earlier demonstrated the existence of positive relationship between marketing research practices and firm's performance. Therefore, our main conclusion is based on the results of this study in which, SMEs growth is influenced by among other things, marketing research practices and different forms of institutions. Although, some marketing literature (e.g. Fu, 2011; Gilmore et al., 2001; Ayanda and Adefemi, 2012; Kohli and Jaworski, 1993) indicate that SMEs' marketing difficulties are due to a lack of sustainable frameworks and severe constraints on SMEs' resources; the results from this study continue to suggest that the majority of SMEs do not include marketing research as part of the formal decisions, and these observed differences are statistically significant at 5 percent level $\left(X^{2}=23.661 ; 2\right.$ d.f. or $p$ value $=0.000$ ).

Further results from an independent $t$-test reveal that a significant difference exist at $5 \%$ level with manufacturing SMEs which adopts structured and formal marketing research being more likely to grow ( $p$-value $=0.009$ ). Thus, hypothesis 1 is not supported. This confirms that the critical role of SMEs owner/managers consist of continuous assessment of a firm's performance and evaluation of competitive advantage aimed at seeking improvement and growth. SMEs need to practice formal marketing research for effective implementation of the marketing programs which in turn induce firm's growth. It is on this account that the underlying marketing theories and various empirical works (Nyamanza, 2019; Simpson et al., 2006; Ebitu, 2016; Oyedijo et al., 2012) are supported.

Notwithstanding, findings continue to support that there are no statistical and significant relationships between the performance of SMEs and the extent of utilising marketing research data generated externally at $5 \%$ level of chi-square statistics $\left(X^{2}=14.975\right.$; 4 d.f. or $p$-value $=0.005)$. Hence, hypothesis 2 is also not supported. This signifies that although the majority of SMEs (87\%) utilises marketing research information from outside agents, they prefer to do it mostly in an informal way due to limited financial resources to pay for quality research reports as well as an increasing pressure posed by competitive environment for business survival.

In the same vein, a linear regression analysis reports that the proposed model for the degree of executing marketing research and SMEs' growth performance is statistically significant though the extent of executing marketing research activities are on average associated with the changes in sales turn-over by 4.84 points. In this perspective, the percentage change in sales turn-over explained by the model is not due to chance since the results reveal a significant value less than 0.05 . Henceforth, hypothesis 3 is supported although the relationship is weak due to a lower adjusted R-square of only $2.9 \%$. This analysis compares with the works of others (e.g. Al Mamun, Mohiuddin, Fazal, and Ahmad, 2018) who insist that a significant relationship exists between higher performance and the reported extent of formal marketing research in New Zealand manufacturing firms.

\section{RECOMMENDATIONS}

The findings of this research have established that a significant relationship exists between growth of small businesses and marketing research activities; and this adds to the existing body of knowledge. Moreover, market orientation theory, contingency, and the evolutionary systems change theories are altogether substantiated by these findings. In this perspective, customers' needs must be identified, scrutinised, and effectively addressed through market research in which, both primary and secondary data sources are of great use. The empirical evidence found in this research confirmed that Tanzanian manufacturing SMEs perceive marketing research as an important activity for competitive market strategies but the majority do it in an informal style. This way, marketing research as an ingredient which influences business is not as well established for smaller manufacturing firms compared with their larger counterparts in Tanzania (see also Nyamanza, 2019).

Evidently, SMEs owner/managers need to continuously provide required trainings to their employees or employ someone who already has the required knowledge and marketing skills so that they may be able to perform formal marketing research to survive in the wider business environment that is seen as challenging. They must employ a more systematic and coordinated approach to the application of the marketing research strategies and specific resources must be allocated for the use of these strategies. Similar views by Ogundele (2000) indicate that Nigerian small and medium entrepreneurs employed several combinations of marketing practices to survive in the external marketing environment that was described as unfriendly.

Likewise, it can be stated that the implementation of marketing practices is necessary in some industries than in others (Walker and Wan, 2012) and therefore, the contingency approach, the market orientation theory, and the evolutionary systems change theories need to be underpinned through SWOT analysis technique when executing marketing activities within manufacturing SMEs. As a result of this, the variable nature of SMEs results in their marketing processes and efforts being unevenly executed. These dynamics and differences cut across all sectors of the economy. Thus, a careful consideration of each sector is required before any support efforts are made. The importance of the implementation of SMEs Development Policy (2003), Tanzania Sustainable Industries Development Policy (1996), and National Trade Policy of 2003 cannot be understated given the contribution 


\section{The Importance of Marketing Research Practices on the Performance of Tanzanian Manufacturing SMEs.}

of SMEs to economic and industrial development (Isaga et al., 2015; Nyiti, 2001; URT, 2014; Mdasha et al., 2018). For the efficacy of the underlying national policies, the formation of business steering instruments which is responsible for coordinating SMEs activities and make follow-ups to appraise their development efforts is suggested. Also, the role of training institutions and colleges in spearheading marketing processes and research skills in SMEs is recommended.

Subsequently, business partnerships are a way forward to strengthen SMEs in Tanzania. The findings reveal that the low number of foreign companies are operating in Tanzanian manufacturing SMEs. So, the government needs to take measures to encourage and increase more joint venture activities with foreign firms, which in turn will have impact on improving rapid adoption and diffusion of marketing techniques and research skills within SMEs.

\subsection{Limitations and areas for future research.}

In this study, only marketing research issues specific for manufacturing SMEs in Dar es Salaam, Tanzania have been explored. Other issues such as e-marketing, marketing mix processes, marketing planning, and services marketing (to mention a few) were not dealt with. To this end, the need to have a much more focused study in other empirical settings in order to uncover insights is recommended. For the same reason, future research on other sectors like financial, agricultural, and commercial and tourist need to be investigated. Since the study utilised a perceptual growth measures of performance based on the opinions of the owners/managers of SMEs; there is possibility of a bias in giving an accurate picture regarding SMEs performance. Thus, the respondents' response may have been influenced by other situational factors and so, the current study suffers from such limitations, which contradicts with the reliability of the findings.

In response to this, testing of reliability using Cronbach's alpha coefficient with value greater than 0.7 for growth indicators is considered appropriate before the instrument is employed for fitting the required model for analysis. Although the view to perceptual measurements of growth have been used by several researchers and have been shown to correlate highly with objective measurements (Mahemba, 2003; Isaga, 2012) the use of more objective measures of performance in other similar studies is recommended. Likewise, explanatory design through cross-section and single sector research approaches have been applied and provided robust results. Other studies using an experimental research design and/or longitudinal data collection method are recommended.

\section{REFERENCES:}

1) Adewale, G., Adesola, M.A., and Oyewale, I.O. (2013). Impact of Marketing Strategy on Business Performance. A study of selected Small and Medium Enterprises (SMEs) in Oluyole local government, Ibadan, Nigeria. IOSR Journal of Business and Management, Vol. 11 (No. 4), pp. 59 - 66

2) Al Mamun, A., Mohiuddin, M., Fazal, S.A., and Ahmad, G.B. (2018). "Effects of entrepreneurial and market orientation on consumer engagement and performance of manufacturing SMEs", Management Research Review, Vol. 41 (No. 1), pp. $133-147$

3) American Marketing Association-AMA (2013). Definition of Marketing. Chicago: AMA. Available at: https://www.ama.org/AboutAMA/Pages/Definition-of-Marketing.aspx (accessed on 2nd March, 2021)

4) Anderson, W. (2011). Internationalization Opportunities and Challenges for Small and Medium-sized Enterprises from Developing Countries. Journal of African Business, 12(2), 198-217. https://doi.org/10.1080/15228916.2011.588912

5) Anderson, W. (2012). A Gender-Based Comparison of Marketing Strategies of SMEs in Tanzania. International Journal of Marketing Principles and Practices, 2(1), 32-42.

6) Anderson, W. (2017). Factors affecting Small and Medium Enterprises (SMEs) start-up and Growth in Tanzania. The Pan African Journal of Business Management, 1(1), 1-26.

7) Ayanda, A.M., and Adefemi, B.J. (2012). Marketing mix practice as a Determinant of Entrepreneurial Business Performance. International Journal of Business Management, Vol. 7(No. 1), pp. 205 - 213.

8) Aziz, N., and Yassin, N. . (2010). How will market orientation and external environment influence the performance among SMEs in the agro-food sector in Malaysia? International Business Research Journal, Vol. 3(No. 3), pp. 154 - 164.

9) Baines, P., Fill, C., and Page, K. (2011). Marketing (2nd ed.), Oxford University Press.

10) Blumberg, B., Cooper, R., and Schindler, P.S. (2011). Business Research Methods ( $3^{\text {rd }}$ ed.). London, United Kingdom: McGraw-Hill Education.

11) Blythe, J. (2006). Principles and Practice of Marketing. London, UK: Thomson.

12) Brooksbank, R. (1991). "Defining the Small Business: A new classification of company size". Entrepreneurship and Regional Development, Vol. 3(No. 1), pp. 17 - 32.

13) Brooksbank, R., Garland, R., and Taylor, D. (2008). Strategic Marketing Practices: Their contribution to the competitive success of medium-sized manufacturing firms in New Zealand. Small Enterprise Research. 
The Importance of Marketing Research Practices on the Performance of Tanzanian Manufacturing SMEs.

14) Bryman, A., and Bell, E. (2011). Business Research Methods ( $3^{\text {rd }}$ ed. ). New York: Oxford.

15) Buli, B.M. (2017). "Entrepreneurial Orientation, Market Orientation, and Performance of SMEs in the Manufacturing industry: Evidence from Ethiopian enterprises". Management Research Review, Vol.40 (No.3), pp. 292 - 309

16) Carson, D., Gilmore, A., and Rocks, S. (2004). "SMEs Marketing networking: A strategic Approach". Strategic change, Vol. 13, pp.369 - 382.

17) Churchill, G. (1996). Basic Marketing Research (3 $3^{\text {rd }}$ ed.), Dryden Press.

18) Cooper, D.R., and Schindler, P.S. (2003). Business Research Methods, McGraw-Hill Companies

19) Cooper, R.G., and Kleinschmidt, E.J. (2015). "The Impact of export strategy on export sales performance". Journal of International Business Studies, Vol.3 (No.2), pp. 37 - 55

20) De Waal, A. (2012). "What makes a high performance organisation: Five validated factors of Competitive advantage that apply worldwide". Kent TN 185AD , UK: Global Professional Publishing Limited. ISBN: 978-1-906403-82-9

21) Dragnić, D. (2009). Marketing activities of small businesses in Croatia: The case of Splitsko-Dalmatinska County. Management Journal, Vol. 14 (No. 1), pp. 39 - 58.

22) Ebitu, T.M. (2016). "Marketing Strategies and the Performance of Enterprises in Akwa-lbom state, Nigeria”. British Journal of Marketing Studies, Vol. 4 (No. 5), pp. 51 - 62

23) Fu, Y. (2011). Marketing activities management in SMEs: An exploratory study. Human systems management Journal , Vol. 30, pp. 155 - 166.

24) Gati, M.G. (2015). Influencing factors of Small and Medium Sized Enterprises' marketing activities - In particular as regards on online marketing activities: A PhD Dissertation, Doctoral School of Management and Business Administration, University of Budapest.

25) Ghouri, A., Khan, N., and Razzaq, A. (2011). Marketing Practices and their effects on firm's performance: Findings from Small and Medium sized catering and restaurants in Karachi. International Journal of Business and Management, Vol. 6 (No. 5), pp. 251 - 260.

26) Gilmore, A., Carson, D., and Grant, K. (2001). "SMEs Marketing in Practice." Marketing Intelligence and Planning, Vol. 19 (No. 1), pp. $6-11$.

27) Gupta, V.K., and Batra, S. (2016). “Entrepreneurial Orientation and Firms Performance in Indian SMEs: Universal and Contigency Perspective". International Small Business Journal, Vol.34(No.5), pp.660-682

28) Hair, J.F., Black, W.C., Babin, B.J., Anderson, R.E., and Tatham, R.L. (2006). Multivariate Data Analysis. Prentice-Hall, Englewood Cliffs.

29) Isaga, N. (2012). "Entrepreneurship and the growth of SMEs in the furniture industry in Tanzania". PhD Thesis, Amsterdam: Vrije University.

30) Isaga, N., Masurel, E., and Montfort, K.V. (2015). “Owner-manager motives and the growth of SMEs in developing countries: Evidence from the furniture industry in Tanzania", Journal of Enterpreneurship in Emerging Economies, Vol.7 (No.3), pp. 190 - 211, https://doi.org/10.1108/JEEE-11-2014-0043

31) Jaworski, B.J., and Kohli, A.K. (1993). "Market orientation: Antecedents and Consequences". Journal of Marketing, Vol. 57, pp. $53-70$.

32) Jayashankar, P. (2013). The Impact of marketing strategies on the social and financial performance of Micro finance Institutions. DBA Dissertation, Maastricht School of Management: Maastricht, The Netherlands.

33) Kiveu, M., and Ofofa, G. (2013). "Enhancing Market Access in Kenyan SMEs using ICT”. Global Business and Economic Research Journal, Vol.2(No.9), pp. 29-46.

34) Kiyabo, K., \& Isaga, N. (2019), Strategic entrepreneurship, competitive advantage, and SMEs Performance in the welding industry in Tanzania. Journal of Entrepreurship Research, 9(62), 1-23. https://doi.org/10.1186/s40497-019-0188-9

35) Kohli, A.K., and Jaworski, B.J. (1991). "Marketing Orientation: The construct, research propositions, and managerial implications". Journal of Marketing, Vol.54, pp.1-18.

36) Kotler, P. (2001). Principles of Marketing (9 $9^{\text {th }}$ ed.). USA: Prentice - Hall International.

37) Kotler, P., Wong, V., Sunders, J., and Armstrong, G. (2008). Principles of Marketing ( $5^{\text {th }}$ edition). Prectice-Hall, Harlow.

38) Mahemba, C.M. (2003). Innovation Management Practices of Small and Medium Enterprises in Tanzania: PhD Thesis, University of Twente. Enschede, The Netherlands: Grafisch Centrum Twente.

39) Mahemba, C.M., and De Bruijin, E.J. (2003). Innovation Activities by SMEs manufacturing industries in Tanzania. Creativity and Innovation management, Vol. 12(No.3), pp. 162 - 173.

40) Mbamba, U.O.L. (2003). Problems and Perspectives of Information Systems Management in Small and Medium Enterprises in Tanzania: Theoretical foundations, PhD Thesis, UMEA School of Business and Economics, UMEA. 
The Importance of Marketing Research Practices on the Performance of Tanzanian Manufacturing SMEs.

41) Mbura, O. (2008). The Role of Entrepreneurial Networks in the Acquisition of Marketing Information Resources: "Selected Small Manufacturing firms in Tanzania". A PhD thesis, Dar es Salaam: UDBS.

42) Mdasha, Z., Irungu, D., \& Wachira, M. (2018). Effects of Financial Inclusion Strategy on Performance of Small and Medium Enterprises: A case of Selected SMEs in Dar es Salaam, Tanzania. Journal of Strategic Management, 2(1), 51-70.

43) McLarty, R., Pichanic, M., and Srpova, J. (2012). "Factors Influencing the Performance of Small to Medium-Sized Enterprises: An empirical study in the Czech Republic". International Journal of Management, Vol. 29, No.3, pp. 36 - 47.

44) Nyamanza, U. B. C. (2019). Marketing practices and Their Effects on SMEs Growth In Tanzania: The Case of Small and Medium Manufacturing Firms (DBA Thesis). Maastrictch School of management, The Netherlands.

45) Nyamanza, U.B.C. (2020). "Exploring Marketing Mix Practices of the Tanzanian Manufacturing SMEs and Their Growth Dynamics". Journal of Economics, Trade and Marketing Management, Vol.2 (No.4), pp. 13 - 37. Doi: 10.22158/jetmm. V2n4p13

46) Nyiti, A. (2001). "The SMEs Promotion Policy in Tanzania". A paper presented for Training on Management and Development of SMEs, Faculty of Commerce and Management, $19^{\text {th }}-30^{\text {th }}$ March: University of Dar es Salaam.

47) O’Dweyer, M., Gilmore, A., \& Carson, D. (2009). Innovative Marketing in SMEs: An empirical study. Journal of Strategic Marketing, Vol. 17(No. 5), pp. 383 - 396.

48) Ogbu, C.P. (2017). "Marketing Strategies and Performance of Indigenous Construction Firms in Nigeria". Journal of Construction in Developing Countries , Vol.22 (1), pp. 1-19

49) Ogundele, O.J.K., Akingbade, W.A., Saka, R.O., Elegunde, A.F., and Aliu, A.A. (2013). Marketing Practice of Small and Medium Enterprises (SMEs): Perspective from a Developing Country. Mediterranean Journal of Social Sciences, Vol. 4 (No.3), pp. $243-258$.

50) Olomi, D. (1999). Entrepreneurial Characteristics and Small Firm Performance. In Rutashobya, L., and Olomi, D. (Ed). African Entrepreneurship and Small Business Development (pp. 161 - 180), Dar es Salaam, Tanzania: Dar es Salaam University Press.

51) Olomi, D. (2001). "Entrepreneurial motivation in developing country context: Incidence, antecedents and consequences of growth seeking behaviour among Tanzanian owner-managers". A PhD dissertation, University of Dar es Salaam, Tanzania: Dar es Salaam University Press.

52) Olomi, D. (2006). “Opportunities and Challenges for Rural SMEs development in Tanzania". Policy Dialogue Seminar Paper, Dar es Salaam: Economic and Social Researh Foundation.

53) Owomoyela, S.K., Oyeniyi, K.O., and Ola, O.S. (2013). "Investigating the Impacts of Marketing Mix Elements on Consumer Loyalty: An Empirical Study on Nigerian Breweries Plc." Interdisciplinary Journal of Contemporary Research in Business. Vol. 4 (No. 11), pp. $485-496$

54) Oyedijo, A., Idris, A.A., and Aliu, A.A. (2012). "Impacts of Marketing Practices on the Performance of Small Business Enterprises: Empirical Evidence from Nigeria," European Journal of Economics, Finance and Administrative Sciences. Vol. 46, ISSN 1450-2275

55) Panayidas, P.M. (2004). Marketing in Asia - Pasific Logistics Companies: A Discriminant Analysis between Marketing Orientation and Performance, Asia Pacific Journal of Marketing and Logistics, Vol. 16 (No.1), pp. $42-68$

56) Resnick, S.M., Cheng, R., Simpson, M., and Lourenco, F. (2016). "Marketing in SMEs: A 4P's self branding model." International Journal of Entrepreneurial Behavior and Research, Vol. 22 (No.1), pp. 155 - 174

57) Royse, D. (2003). Research Methods in Social Networks, Nelson Hall, Inc.

58) Rutshobya, L. (2001). Female entrepreneurship in Tanzania: Constraints and strategic considerations. Proceedings of the International Academy of African Business Development, (pp.31-37). Washington D.C.

59) Saleh, M.A. (2015). "The role of marketing capabilities in firm's success." International Journal of Management Science and Business Administration. Vol. 2 (No.1), pp. 56-65

60) Saunders, M., Lewis, P., \& Thornhill, A. (2003). Research Methods for Business Students (3 ${ }^{\text {rd }}$ ed.). Harlow, UK: Prentice Hall.

61) Shiraz, M.S. (2017). "Study on the Roles of Electronic Marketing on Business Performance with emphasis on the role of market orientation". International Review of Management and Marketing. ISSN: 2146-4405, Vol. 7 (No. 3 ), pp. 357 - 365

62) Simpson, M., Padmore, J., Taylor, N., and Frecknall-Hughes, J. (2006). Marketing in Small and Medium Sized Enterprises. International Journal of Entrepreneurial Behaviour and Research, Vol.12(No.6), pp.316- 387

63) Siu, W. (2002). Marketing activities and performance: A comparison of the internet-based and traditional small firms in Taiwan. Industrial Marketing Management, Vol. 31, pp. 177 - 188. 
The Importance of Marketing Research Practices on the Performance of Tanzanian Manufacturing SMEs.

64) Siu, W., Fang, W., and Lin, T. (2004). Strategic Marketing practices and the performance of Chinese SMEs in Taiwan. Entrepreneurship and Regional Development Journal, pp. 161-178.

65) Sohail, M.S., and Alashban, A.A. (2009). "An analysis of Product-Market Strategy and Export Performance: Evidence from SME's in Saudi Arabia". International Journal of Entrepreneurship, Vol.13 (Special Issue), pp.49-65.

66) Stokes, D., and Wilson, N.C. (2010). “Entrepreneurship and Marketing Education: Time for the roadless travelled?" International Journal of Entrepreneurship and Innovation Management, Vol.11(No.1), pp.95 -108.

67) TCCIA. (1995). Tanzania Business Contacts, 1995/96,. Dar es Salaam: Tanzania Chamber of Commerce Industry and Agriculture.

68) Tzokas, N., Carter, S., and Kyriazopoulos, P. (2001). Marketing and Entrepreneurial Orientation in Small Firms. Enterprise and Innovation Management Studies, Vol.2(No. 1), pp. 19 - 33.

69) URT . (2014). Economic Review and Operations Annual Report. Dar es Salaam: Tanzania Bureau of Statistics and Bank of Tanzania

70) United Republic of Tanzania (URT), Ministry of Industry and Trade. (2003). Small and Medium Enterprises Development Policy 2003-2013. Dar es Salaam, Tanzania: Government printer.

71) URT. (2009). "Tanzania Key Statistics". Dar es Salaam, Tanzania: National Bureau of Statistics.

72) URT. (2012). Tanzania Long-term Perspective Plan 2011/12 - 2025/26: The Road map to Middle Income Country. Dar es Salaam: Presidents Office, Planning Commission.

73) Walker, K., and Wan, F. (2012). "The Harm of Symbolic Actions and Green-washing: Corporate Actions and Communications on Environmental performance and their financial implications." Journal of Business Ethics, Vol. 109, pp. 227 - 242, DOI: $10.1007 / \mathrm{S} 10551-011-1122-4$

74) Walsh, M.F., and Lipinski, J. (2009). The Role of the Marketing Functions in Small and Medium Sized Enterprises. Journal of Small Business and Enterprises Development, Vol. 16 (No.4), 569 - 585.

75) Zikmund, W. (2000). Business Research Methods (6th ed.). Harcourt College, Fort worth: The Dryden Press. 